\title{
Preparation and Characterization of a Hydrophilic Polysulfone Membrane Using Graphene Oxide
}

\author{
Hoan Thi Vuong Nguyen $\left(D,{ }^{1}\right.$ Thu Hong Anh Ngo $\left(D,{ }^{2}\right.$ Khai Dinh Do, ${ }^{2}$ Minh Ngoc Nguyen, ${ }^{1}$ \\ Nu Thi To Dang, ${ }^{1}$ Tham Thi Hong Nguyen, ${ }^{3}$ Vo Vien $\mathbb{D}^{1},{ }^{1}$ and Tuan Anh Vu $\mathbb{D}^{4}$
}

${ }^{1}$ Faculty of Chemistry, Quy Nhon University, Quy Nhon, Vietnam

${ }^{2}$ Faculty of Chemistry, VNU University of Science, Hanoi, Vietnam

${ }^{3}$ NTT Hi-Tech Institute, Nguyen Tat Thanh University, Ho Chi Minh City, Vietnam

${ }^{4}$ Institute of Chemistry, Vietnam Academy of Science and Technology, Ha Noi, Vietnam

Correspondence should be addressed to Hoan Thi Vuong Nguyen; nguyenthivuonghoan@qnu.edu.vn and Thu Hong Anh Ngo; anhthu@hus.edu.vn

Received 1 March 2019; Revised 13 May 2019; Accepted 21 May 2019; Published 13 June 2019

Guest Editor: Van Duong Dao

Copyright (c) 2019 Hoan Thi Vuong Nguyen et al. This is an open access article distributed under the Creative Commons Attribution License, which permits unrestricted use, distribution, and reproduction in any medium, provided the original work is properly cited.

\begin{abstract}
In general, the polysulfone (PSf) membranes are popular choices for water treatment because they have high thermal stability and good chemical resistance. On the other hand, the filtration capacity of the polysulfone membrane is limited because of its low water flux and poor antifouling ability, which are caused by the low surface hydrophilicity of the membranes. In this research, blending of graphene oxide $(\mathrm{GO})$ or graphene oxide-titanium dioxide $\left(\mathrm{GO}-\mathrm{TiO}_{2}\right)$ mixture into the polysulfone matrix had been carried out through the phase inversion method to enhance the hydrophilic and antifouling properties. Methods such as energydispersive X-ray spectroscopy, scanning electron microscopy, Fourier transform infrared spectroscopy, and water contact angle measurement were used to examine the surface properties of the prepared membranes. Experimental results have led to a conclusion that graphene oxide can be stabilized into prepared membranes, and then, by reducing the water contact angle values, the surface of these membranes becomes hydrophilic, which increases the permeability and the water flux of methylene blue from the aqueous feed solution, improving the membrane's antifouling resistance.
\end{abstract}

\section{Introduction}

Today, membranes and membrane processes have been applied in cleaning technology and the environmental field $[1,2]$. Efficiency and utility from membrane applications have led to the need for new membrane materials with properties suitable for their applications. Therefore, the type of material selected and the method of membrane preparation are the determining factors for the properties of the membrane.

Polysulfone (PSf) is the preferred choice in membrane fabrication, and its prominence is derived from chemical resistance, wide operating temperature and $\mathrm{pH}$, and high mechanical strength [2-5]. However, at present, the operating costs of PSf membrane processes are still quite high because of fouling, limitations on filtering capacity, and longevity, which are due to their high hydrophobic properties $[2-4,6,7]$. Recently, the increase in hydrophilicity and the minimization of fouling of PSf membranes have been tested through a variety of solutions including modifying the surface $[8,9]$, coating onto the membrane surface [10-14], and blending the hydrophilic materials into the membrane casting solution before fabricating the membrane $[2,5,15-20]$. Among the aforementioned methods, the method of blending PSf with some hydrophilic polymers or inorganic nanoparticles to increase the surface hydrophilic and antifouling properties has proven remarkably effective $[2,5,20-23]$.

Zodrow et al. [21] blended nanosilver particles into the matrix of the PSf membrane to increase the membrane 
hydrophilicity and reduce the biofouling and virus penetration. By using the phase inversion method, Kang et al. [2] prepared more hydrophilic PSf/SGO (sulfonated graphene oxide) membranes. After conducting the tests, the researchers found that mixing $1.5 \mathrm{w} / \mathrm{w} \% \mathrm{SGO}$ into the PSf matrix made this membrane reach a water flux higher than $125 \%$ compared to that of the PSf membrane. Prabhu et al. [5] blended the chitosan derivative 1H-pyrazole-4carbaldehyde into the PSf matrix by the wet coagulation method. These observations indicate that hydrophilic groups (such as hydroxyl, amine, and imine) improved the hydrophilicity of the blended membrane as they cause a decrease in the contact angle (from $70 \pm 1^{\circ}$ of the PSf membrane down to $62 \pm 1^{\circ}$ of blended membranes) and the improvement in water flux (from 24 of the PSf membrane to $351 \mathrm{~L} \cdot \mathrm{m}^{-2} \cdot \mathrm{h}^{-1}$ of the blended membrane at $\left.0.8 \mathrm{MPa}\right)$. Ravishankar et al. [20] blended graphene oxide (GO) nanoparticles into the PSf matrix to prepare PSf/GO membranes. The results showed that the PSf/GO membrane has a better hydrophobicity than the PSf membrane (the contact angle of water is $34.2^{\circ}$ and the permeability is $52.1 \mathrm{~L} \cdot \mathrm{m}^{-2} \cdot \mathrm{h}^{-1} \cdot \mathrm{bar}^{-1}$ ).

Recently, graphene oxide (GO) has been one of the most common hydrophilic inorganic particles that are used for preparing blended membranes $[3,20]$. It has been proven that the appearance of oxygen-containing groups including hydroxyl, epoxy, and carboxyl when fabricating a graphene oxide-blended membrane has shown that the membrane possess high effective flux and better antifouling capacity [20]. The strong hydrogen network with the water molecules is made up of oxygen functionalities, so it creates a strong hydrophilicity $[22,24]$. The combination (blend) of GO into the membrane is prominent in increasing the permeability $[25,26]$ and antifouling [7] and antibacterial [23, 25-30] properties for membrane applications as have been recorded in many previous studies. All results show that GO-blended polymer membranes are more hydrophilic and antifouling than unblended membranes, and it means that GO membranes are hydrophilic [26-28].

To enhance the membrane-blending properties, titanium dioxide $\left(\mathrm{TiO}_{2}\right)$ or other hydrophilic nanoparticle materials are integrated into the polymer membrane by modifying these nanoparticles with GO by the surface hydrothermal method $[29,31]$. Safarpour et al. [32] prepared the reverse osmosis membrane by incorporating the reduced graphene oxide ( $\mathrm{rGO}) / \mathrm{TiO}_{2}$ material onto its surface. The researchers found that the separation efficiency and the antifouling capacity of the membranes increased compared to unblended membranes (water flux improved from 34.3 to $51.3 \mathrm{~L} \cdot \mathrm{m}^{-2} \cdot \mathrm{h}^{-1}$, and antifouling resistance increased from $49 \%$ to $75 \%$ after 180 minutes filtering bovine serum albumin solution). In another article, Faria et al. [33] showed that the growth of bacteria and biofilm on membranes has been prevented by adding silver and graphene oxide to TFC-PA membranes. The reason for the decline in the flux is due to biofilm development, which has decreased by $30 \%$ after incorporating GOAg nanocomposites onto the TFC membrane.

Most polysulfone membranes are prepared by the phase inversion method as other polymer membranes. To begin the membrane forming process, the researchers dissolve the polymer in the solvent or in an organic solvent mixture. Then, the coating solution is spread in the form of a thin layer onto the plate or on a rotating disc, and the next membrane is coagulated in a solvent-free medium to form a porous membrane $[33,34]$. A spin coating method is a technique for making a highly homogeneous membrane [34].

In general, the coating of hydrophilic layers such as GO and $\mathrm{TiO}_{2}$ onto the membrane matrix is an effective method for improving the membrane separation performance.

However, very little information on the preparation of the polysulfone membranes with $\mathrm{GO}$ and $\mathrm{TiO}_{2}$ has been known.

In this study, graphene oxide nanoparticles and graphene oxide/titanium dioxide were blended into the polysulfone matrix to prepare polysulfone/GO (PSf/GO) and polysulfone/GO- $\mathrm{TiO}_{2}$ ( $\mathrm{PSf} / \mathrm{GO}-\mathrm{TiO}_{2}$ ) membranes using the phase inversion method. Effects of $\mathrm{GO}$ and $\mathrm{TiO}_{2}$ on the hydrophilic and antifouling properties of the blended membranes were also compared by determining permeability, retention, flux, and fouling resistance of methylene blue in aqueous solution.

\section{Experimental Methods}

2.1. Materials. Graphene oxide (GO) prepared from graphite powder (Merck) by Hummers' method [35] and $\mathrm{TiO}_{2}$ prepared from tetrachloride $\mathrm{TiCl}_{4}$ (Merck) titanium by the sol-gel method were used as additives in the coating solution. Polysulfone (molecular weight: $22,000 \mathrm{~g} \cdot \mathrm{mol}^{-1}$ ) was used as the original polymer supplied by Sigma-Aldrich in the casting solution. $N, N$-Dimethyl formamide (DMF) purchased from China Science Co., Ltd. was used as a solvent. Methylene blue (MB) (China) has been used to prepare feed solutions for membrane filtration experiments.

2.2. Preparation of PSf, PSf/GO, and PSf/GO-TiO Membranes. The PSf, PSf/GO, and PSf/GO-TiO ${ }_{2}$ membranes were prepared through phase inversion with DMF used as a solvent, $\mathrm{GO}$ and $\mathrm{GO}$-modified $\mathrm{TiO}_{2}$ as additives to prepare PSf/GO and $\mathrm{PSf} / \mathrm{GO}-\mathrm{TiO}_{2}$ membranes, and deionized water as the nonsolvent in the coagulation bath.

Polysulfone and a different amount of GO $(0.0,1.0$, and $2.0 \%$ by weight of PSf) were added to DMF and dissolved for 24 hours at $60^{\circ} \mathrm{C}$ by sonication to obtain a homogeneous mixture, and then to allow the mixture to release all the bubbles, it was left overnight.

To prepare PSf/GO- $\mathrm{TiO}_{2}$ membranes, a different amount of $\mathrm{TiO}_{2}(10,15$, and $20 \%$ by weight of GO) and GO were added to DMF and dissolved for 24 hours at $60^{\circ} \mathrm{C}$ by sonication to obtain a homogeneous mixture and then left overnight.

Using the spin coating method, the solutions are then dripped on clean glass supports (coating speed in the range of 1400 to $2400 \mathrm{rpm}$ ). Then, the solvent is evaporated in 30 seconds, and this solution is soaked in a freezer. After that, the membrane that was formed was peeled off and deionized water was used to wash it in order to remove any 
remaining solvents. Before testing, the blended membranes must be kept carefully in deionized water.

2.3. Characteristics of Materials and Membranes. A D8 Advanced Bruker anode X-ray diffractometer with $\mathrm{CuKa}$ $(\lambda=0.154 \mathrm{~nm})$ radiation using the scanning step of $0.02^{\circ} \cdot \mathrm{s}^{-1}$ in the range of $2^{\circ}$ to $80^{\circ}$ was used to analyze X-ray diffraction (XRD). An electron microscope (SEM-EDX, Nova Nano SEM 450) and a transmission electron microscope (TEM, JEOL 2100F) were used to determine the morphology, size, and elemental mapping of the samples to be summed; the case is characterized by energy-dispersive X-ray spectroscopy. The results of the Fourier transform infrared (FTIR-ATR) spectroscopy method used for samples were recorded on a PerkinElmer spectrophotometer. Water contact angle measurement was used to calculate the moisture content of the unblended and blended membranes via CAM 101/KSV Instruments (Finland), which was used to capture ionized water drops located on the dry surface of the membrane at $25^{\circ} \mathrm{C}$.

2.4. Assessment of Membrane Filtration Properties. Membrane separation tests are performed in a terminal filtration system, including $200 \mathrm{~cm}^{3}$ stainless steel cylindrical cells and a paddle impeller; working pressure in all experiments is 0.87 bar. The filtrate was collected every 5 minutes, and the average throughput was calculated after 90 minutes of filtration. In all experiments, we carefully washed membrane cells with pure water (both before and after use).

Membrane filtration properties are determined through permeability $J_{\mathrm{w}}\left(\mathrm{L} \cdot \mathrm{m}^{-2} \cdot \mathrm{h}^{-1} \cdot \mathrm{bar}^{-1}\right)=\left[V_{\mathrm{w}} /(A t P)\right]$, where $V_{\mathrm{w}}$ is the volume of water through the membrane area of $A$ during the pressure determination of $P$. Ratio of permeability normalization $\left(J_{\mathrm{w}} / J_{\mathrm{w} 0}\right)$, where $J_{\mathrm{w}}$ and $J_{\mathrm{w} 0}$ are the permeabilities of the blended and unblended membranes, was used to examine the improved permeability of the membrane. The flux $\left(J, \mathrm{~L} \cdot \mathrm{m}^{-2} \cdot \mathrm{h}^{-1}\right)$ is evaluated by $J=[V /(A t)]$, where $V$ is the volume of the filtrate. The normalized flux ratio $\left(J / J_{0}\right)$ has been used to determine the enhancement of flux of blended membranes, in which $J$ and $J_{0}$ are the flux of the blended and unblended membranes, respectively. The retention $(R)$ of methylene blue is calculated by $R=\left[\left(C_{0}-C\right) / C_{0}\right] * 100(\%)$, where $C_{0}$ and $C$ are methylene blue concentrations in feed and filtrate, respectively.

2.5. Assessment of Membrane Antifouling Property. The antifouling property was determined via the maintained flux ratios (FM, \%) during filtration. The maintained flux ratio was evaluated by $\mathrm{FM}=\left(J_{t} / J_{t 0}\right) * 100(\%)$, where $J_{t}$ and $J_{t 0}$ are the fluxes of membranes at $t$ time and initial time $\left(\mathrm{L} \cdot \mathrm{m}^{-2} \cdot \mathrm{h}^{-1}\right)$.

\section{Results and Discussion}

3.1. Characteristics of $\mathrm{GO}$ and $\mathrm{GO}-\mathrm{TiO}_{2}$ Nanoparticles. The successful synthesis of $\mathrm{GO}, \mathrm{TiO}_{2}$, and $\mathrm{GO}-\mathrm{TiO}_{2}$ materials has been confirmed through X-ray diffraction (XRD) spectroscopy, scanning electron microscopy (SEM), energy- dispersive X-ray spectroscopy-mapping (EDX-mapping), transmission electron microscopic (TEM) image, and Fourier transform infrared (FTIR) spectral analysis.

3.1.1. X-Ray Diffraction (XRD) Spectrum. Figure 1 shows the XRD spectrum of $\mathrm{GO}, \mathrm{TiO}_{2}$, and $\mathrm{GO}-\mathrm{TiO}_{2}$. The diffraction peak at a lower angle of about $11.4^{\circ} \mathrm{GO}$ implies the introduction of oxygen-containing functional groups of $\mathrm{GO}$ $[36,37]$. However, two broad peaks at about $26^{\circ}$ and $44^{\circ}$ assigned to graphite can clearly see the complete nonoxidation of graphite. Also, Figures 1(a) and 1(b) shows the appearance of a titanium element in the $\mathrm{TiO}_{2}$ and $\mathrm{GO}-\mathrm{TiO}_{2}$ nanoparticles, respectively. We can see that the $\mathrm{TiO}_{2}$ materials appeared in the anatase phase (based on the standard library JCPDS 21-1272), with the occurrence of sharp peaks (101), (004), (105), (211), and (204) at $2 \theta 25.5^{\circ}, 37.0^{\circ}, 54.0^{\circ}$, $56.5^{\circ}$, and $62.5^{\circ}$. Besides, rutile phase also appeared (according to the standard library JCPDS 65-0190) along (110) and (111) at $2 \theta 27.5^{\circ}$ and $41.2^{\circ}$. In Figure $1(\mathrm{~b})$, the characteristic peaks of $\mathrm{GO}$ and $\mathrm{TiO}_{2}$ appeared. Therefore, $\mathrm{GO}$ and $\mathrm{GO}-\mathrm{TiO}_{2}$ were synthesized successfully.

3.1.2. SEM, EDX Mapping, and TEM Images. Figures 2 and 3 display the SEM, EDX-mapping, and TEM images of GO and $\mathrm{GO}-\mathrm{TiO}_{2}$ nanoparticles. The results showed that $\mathrm{GO}$ had a wrinkled surface with some small pieces. This indicated the successful exfoliation of the GO sheet from graphite during graphite oxidation. As can be seen more clearly via the TEM image, there were many layers of GO onto the graphite surface. Thus, the GO material was synthesized successfully from graphite.

SEM images (Figure 3(a1) and 3(a2)) of synthesized GO$\mathrm{TiO}_{2}$ materials showed that the aggregated $\mathrm{TiO}_{2}$ nanoparticles appeared with GO particles. TEM image of GO$\mathrm{TiO}_{2}$ materials showed that the average particle size of $\mathrm{TiO}_{2}$ particles dispersed onto the GO sheet was $10 \mathrm{~nm}$ (Figure 3). Thus, the $\mathrm{GO}-\mathrm{TiO}_{2}$ material was synthesized successfully. EDX-mapping images were used to check the components in the synthesized material. Figures 3(b)-3(d) show that there is a homogeneous distribution of the $\mathrm{C}, \mathrm{O}$, and $\mathrm{Ti}$ elements in the materials.

3.1.3. FTIR Spectra. The FTIR-ATR spectra of GO, $\mathrm{TiO}_{2}$, and $\mathrm{GO}-\mathrm{TiO}_{2}$ are shown in Figure 4. The peaks of GO (Figure 4(a)) were observed via the appearance of $\mathrm{C}-\mathrm{O}$ stretching, $\mathrm{C}=\mathrm{O}$ stretching, and $\mathrm{O}-\mathrm{H}$ stretching, which include the bands at $1050 \mathrm{~cm}^{-1}, 1720 \mathrm{~cm}^{-1}$, and $3350 \mathrm{~cm}^{-1}$ after oxidizing graphite into GO. These groups are hydrophilic. Thus, GO is also hydrophilic. Moreover, the spectrum of $\mathrm{TiO}_{2}$ (Figure 4(b)) and $\mathrm{GO}-\mathrm{TiO}_{2}$ (Figure 4(c)) showed peaks at approximately $580-1000 \mathrm{~cm}^{-1}$ attributed to Ti-O-Ti stretching [38], showing the successful synthesis of $\mathrm{TiO}_{2}$ particles into the $\mathrm{GO}-\mathrm{TiO}_{2}$ material.

3.2. Membrane Characteristics. After preparation of unblended and blended membranes with GO and $\mathrm{GO}-\mathrm{TiO}_{2}$, the hydrophilic ability of membranes was evaluated through 


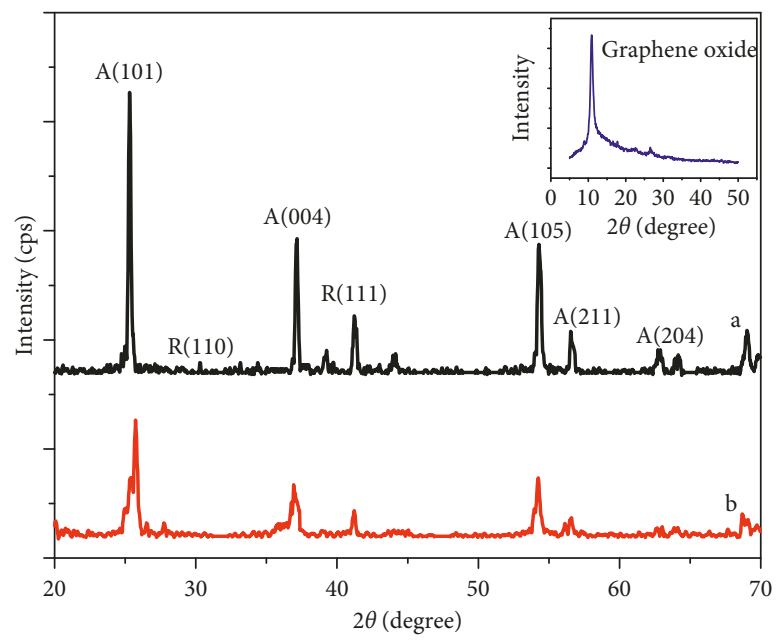

Figure 1: XRD spectrum of GO (inset), $\mathrm{TiO}_{2}$ (a), and $\mathrm{GO} / \mathrm{TiO}_{2}$ (b).

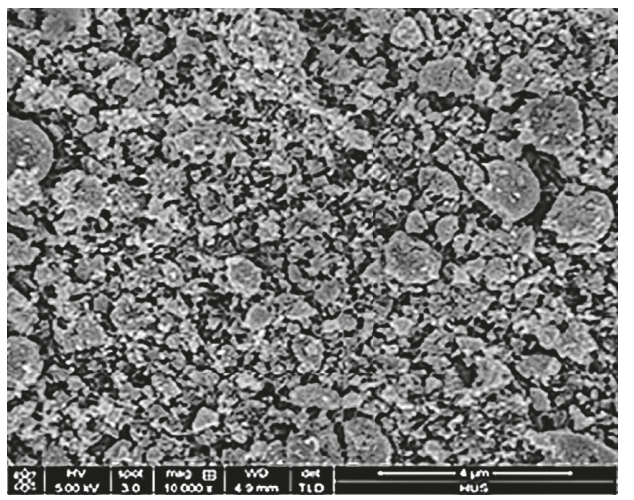

(a)

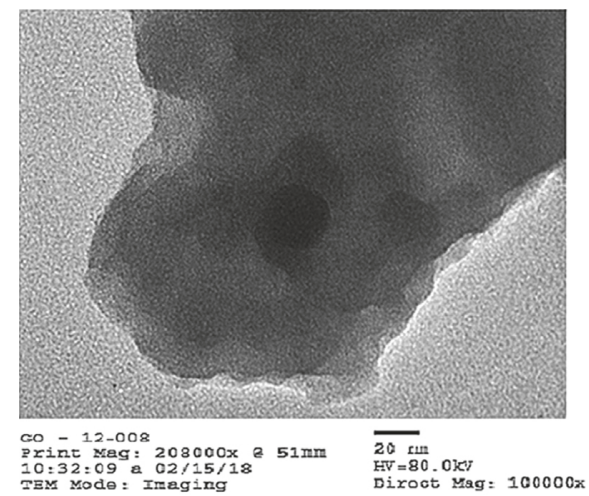

(b)

Figure 2: SEM and TEM images of GO.

scanning electron microscopy (SEM), energy-dispersive X-ray (EDX) spectroscopy analysis, Fourier transform infrared (FTIR) spectroscopy analysis, and water contact angle (WCA) measurement.

3.2.1. SEM Images. SEM images of PSf, PSf/GO, and PSf/ GO- $\mathrm{TiO}_{2}$ membranes with various amounts of $\mathrm{TiO}_{2}(10,15$, and 20 wt.\% based on the weight of GO) are displayed in Figure 5.

Following the cross-sectional images, the PSf membrane has a porous structure with the dense skin layer and the membrane thickness was $64 \mu \mathrm{m}$. Adding GO to the membrane leads to a dramatic change in the PSf membrane structure. Figure 5 shows that GO is deposited onto the membrane surface, and the dispersed grain structure appeared smooth. GO particles make the membrane thickness higher $(79 \mu \mathrm{m})$. With the increased addition of $\mathrm{TiO}_{2}$ to the polymer matrix, surface roughness and membrane thickness increase continuously (from 87.0 to $96.7 \mu \mathrm{m})$. It is clear that $\mathrm{GO}$ and $\mathrm{TiO}_{2}$ nanoparticles are uniformly dispersed in the PSf matrix. In the higher content of $\mathrm{TiO}_{2}$, the holes have disappeared; the surface of the blended membrane becomes thicker than that of the unblended membrane.

The formations of materials containing both hydrophilic $\mathrm{GO}$ and $\mathrm{TiO}_{2}$ can lead to changes in chemical functionality and separation performance of the membrane.

3.2.2. FTIR-ATR Spectrum. Characteristics of the membrane surface were investigated by FTIR spectroscopy, and FTIR-ATR technique was used to demonstrate the successful incorporation of $\mathrm{GO}$ and $\mathrm{TiO}_{2}$ into the polymer matrix of membranes.

Absorptions of the polysulfone layer are characterized by $\mathrm{O}=\mathrm{S}=\mathrm{O}\left(1000-1300 \mathrm{~cm}^{-1}\right)$ and $\mathrm{C}=\mathrm{C}\left(1400-1600 \mathrm{~cm}^{-1}\right)$ for the polysulfone membrane (Figure 6(a)). The appearance of oxygen-containing groups of GO such as $\mathrm{C}-\mathrm{O}$ stretching $\left(1674 \mathrm{~cm}^{-1}\right)$ and $\mathrm{C}=\mathrm{O}$ stretching $\left(1101 \mathrm{~cm}^{-1}\right)$ was observed using spectroscopy (Figure 6(b)) for the blended PSf/GO membrane. With the existence of oxygen-containing groups of GO, the spectroscopy (Figure 6(c)) exhibits a new peak at $600-1000 \mathrm{~cm}^{-1}$ for the blended PSf/GO-TiO 2 membrane, which attributes to the Ti-O-Ti stretching $[39,40]$; it shows the successful 

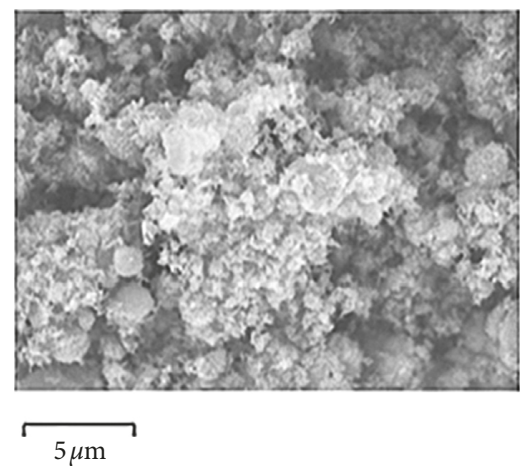

(a1)

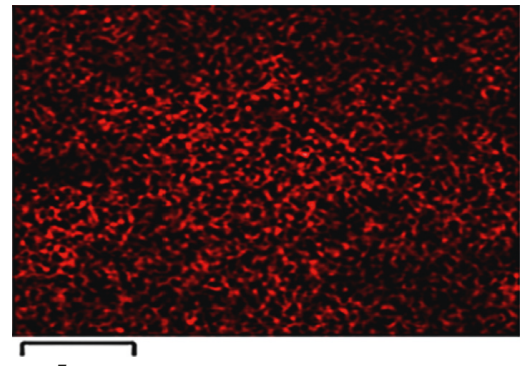

$5 \mu \mathrm{m}$

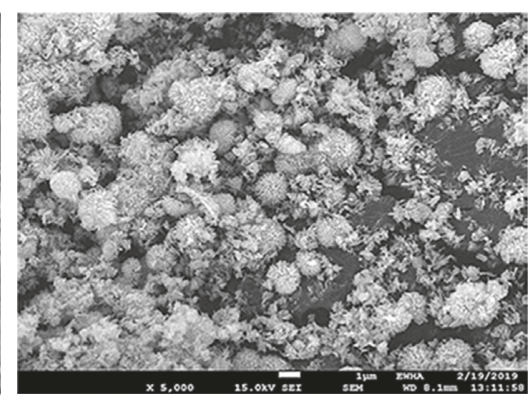

(a2)

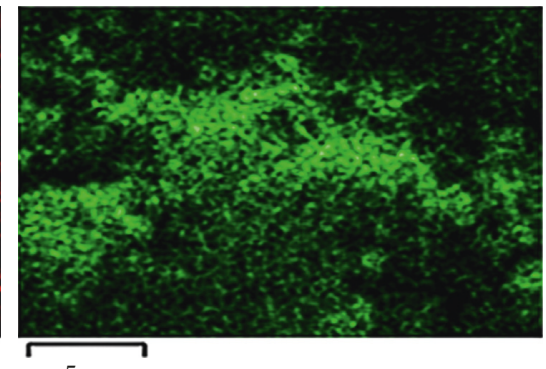

$5 \mu \mathrm{m}$

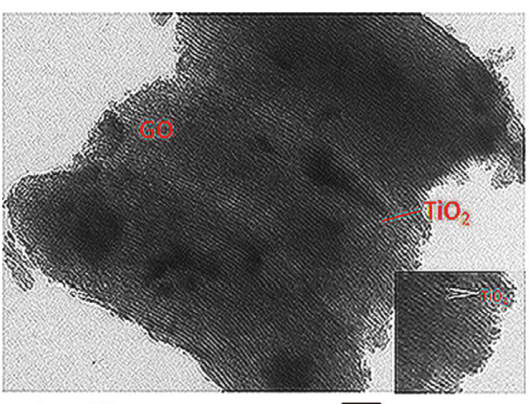

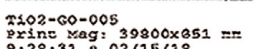

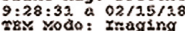

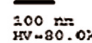
DIXoce Yag : $20000 x$

(a3)

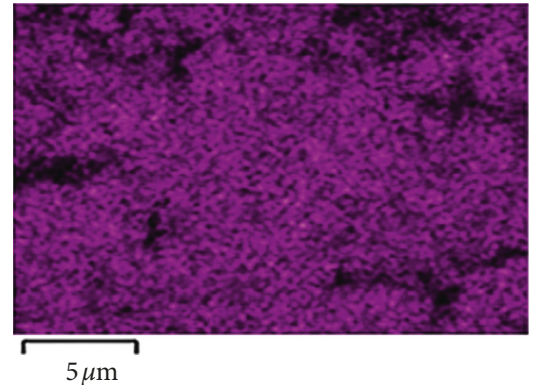

(d)

(b)

(c)

Figure 3: SEM (a1, a2), TEM (a3), and EDX-mapping images of C K series (b), O K series (c), and Ti $\mathrm{K}_{\text {series }}(\mathrm{d})$ elements of GO-TiO 2 materials.

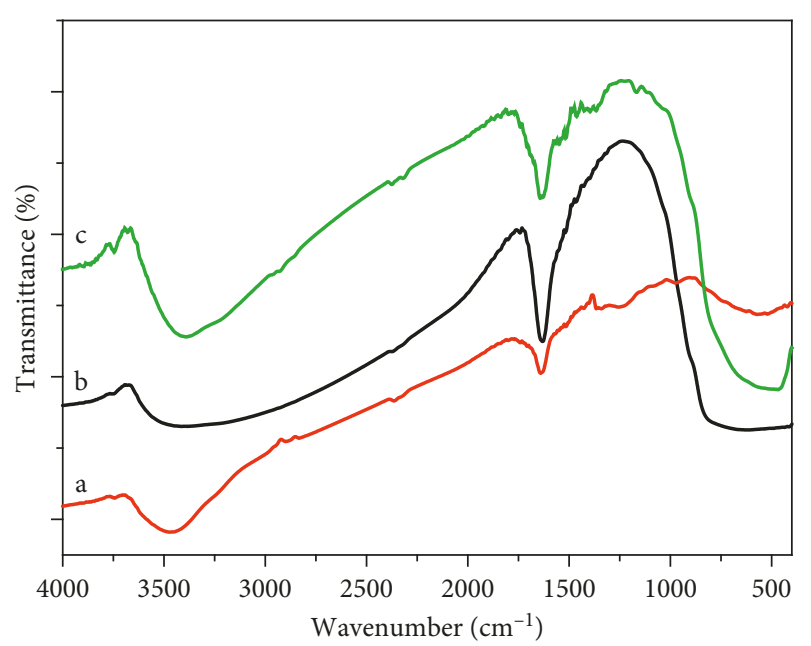

Figure 4: FTIR spectra of $\mathrm{GO}(\mathrm{a}), \mathrm{TiO}_{2}(\mathrm{~b})$, and $\mathrm{GO}-\mathrm{TiO}_{2}$ (c) materials.

blending of $\mathrm{TiO}_{2}$ and $\mathrm{GO}$ particles into the PSf membrane. Thus, the reason why the membrane becomes hydrophilic is the presence of $\mathrm{GO}$ and $\mathrm{TiO}_{2}$.

3.2.3. EDX Analysis. To study the amount of elements of membranes, EDX had been conducted. Figure 7 shows the EDX spectra of unblended and blended membranes and the changes in the proportion of each element.

As can you see, compared to the PSf membrane (Figure 7(a)), the PSf/GO membrane (Figure 7(b)) increased oxygen (from $9.76 \%$ to $19.26 \%$ ) atomic ratio, but carbon and sulfur ratios were decreased (with a sharp decrease of $\mathrm{C}$ atoms from $87.85 \%$ to $79.34 \%$ and a sharp decrease of $\mathrm{S}$ atoms from $2.39 \%$ to $1.40 \%$ ). For the PSf/GO-TiO 2 membrane (Figure $7(\mathrm{c})$ ), the oxygen atomic ratio increased to $33.99 \%$ and carbon atomic ratio decreased to $64.79 \%$; meanwhile, the $\mathrm{Ti}$ atomic ratio was $0.08 \%$. These results proved that $\mathrm{GO}$ and $\mathrm{TiO}_{2}$ nanoparticles exist on the PSf membrane.

3.2.4. Water Contact Angle Measurement. Changes in the water flux of membranes as a result of blending of hydrophilic materials ( $\mathrm{GO}$ and $\mathrm{TiO}_{2}$ ) were investigated via the water contact angle (WCA) measurements. Figure 8 shows the WCAs of the unblended and blended membranes. The results indicated that, by adding $\mathrm{GO}$ and $\mathrm{TiO}_{2}$ into the PSf matrix, the blended membranes became more hydrophilic with a significant decrease of the WCA (Table 1), reducing from $83.4^{\circ}$ for the unblended membrane to around $60.2^{\circ}$ for the blended ones, which is because of the formation of the hydrophilic material on the blended membrane. Thus, the increase of the hydrophilic groups on the membrane reduced the water contact angle values. The obtained results imply that the presence of the GO and $\mathrm{TiO}_{2}$ improves the hydrophilicity of the membrane.

3.3. Membrane Filtration Property. Indeed, with the appearance of the oxygen-containing groups of $\mathrm{GO}$ and $\mathrm{TiO}_{2}$, 

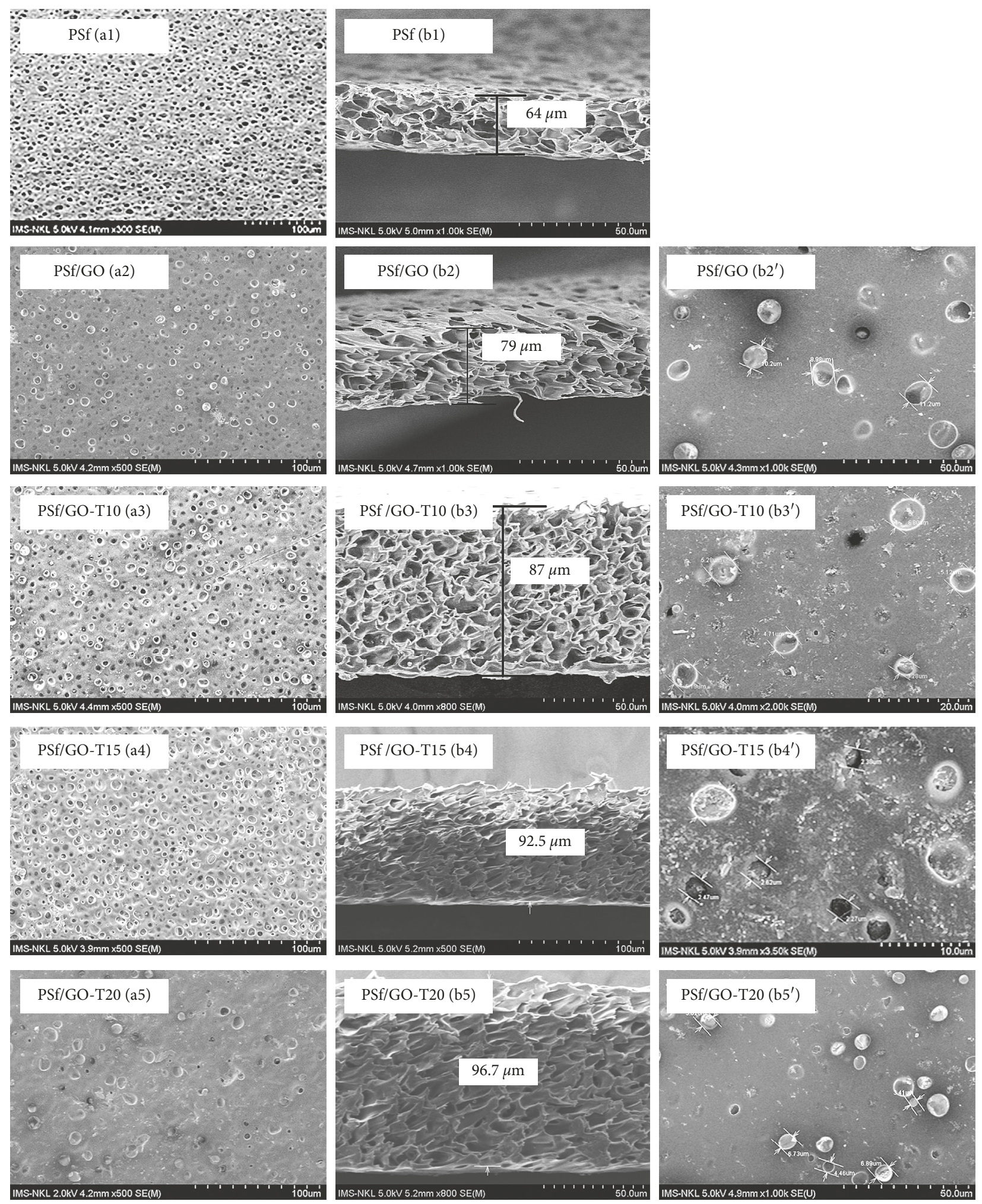

Figure 5: SEM images of the surface (a1, a2, a3, a4, a5; b2', b3', b4 ', b5') and the cross-sectional images (b1, b2, b3, b4, b5) of PSf, PSf/GO, and $\mathrm{PSf} / \mathrm{GO}-\mathrm{TiO}_{2}$ membranes.

the blended membranes became more hydrophilic, and the obtained experimental results related to membrane separation performance are shown below.
3.3.1. Permeability. The permeability can be selected to characterize the changes in the hydrophilic property of the membrane surface. The permeability of the membrane will 


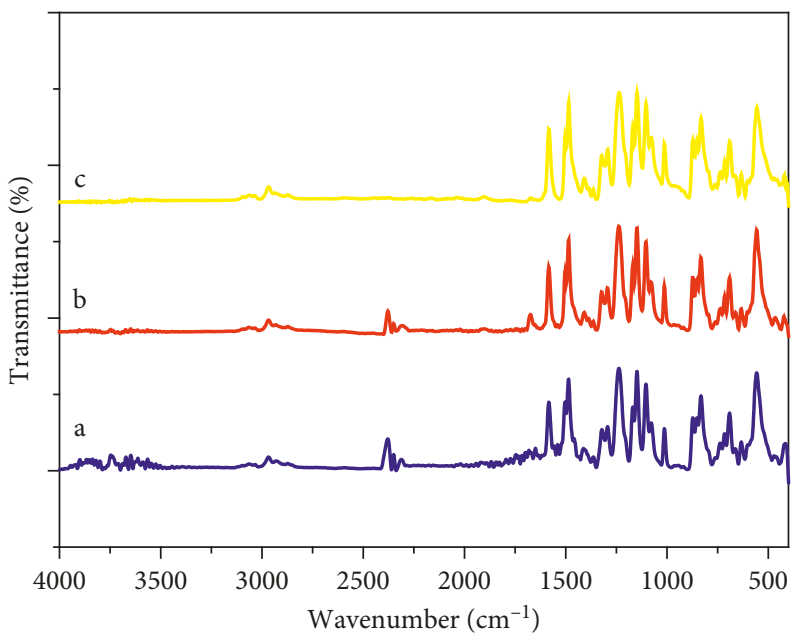

Figure 6: FTIR-ATR spectra of PSf (a), PSf/GO (b), and PSf/GO-T15 (c) membranes.

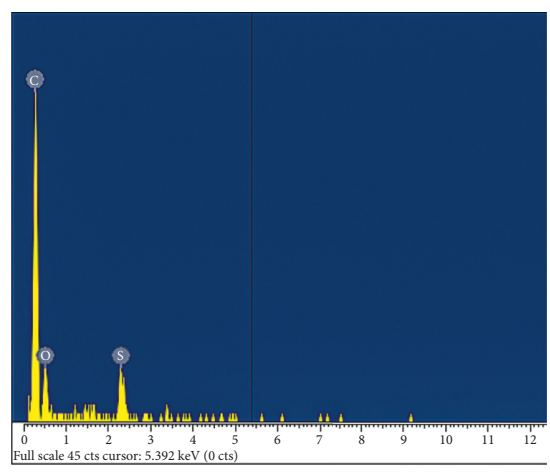

(a)

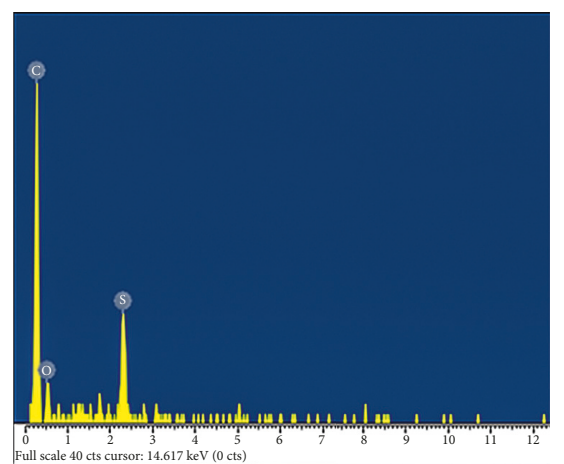

(b)

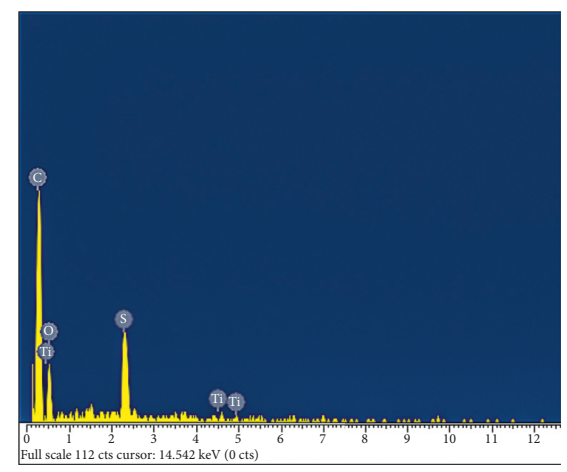

(c)

Figure 7: EDX spectra of PSf (a), PSf/GO (b), and PSf/GO-T15 (c) membranes.
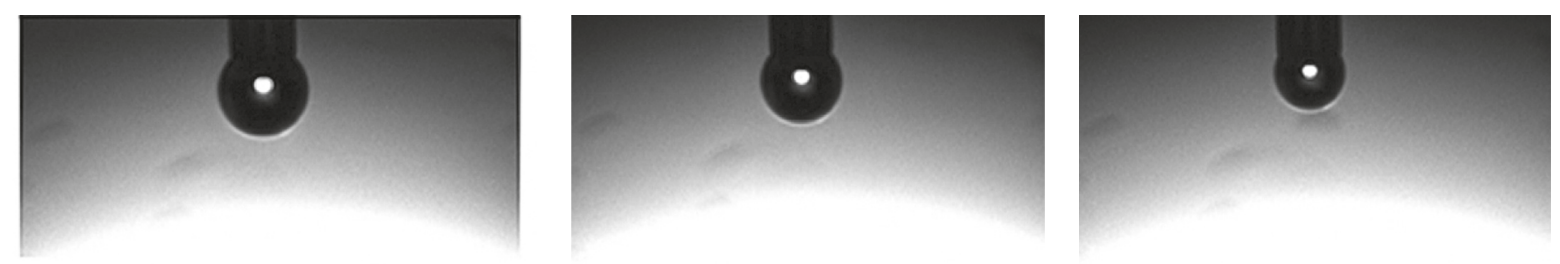

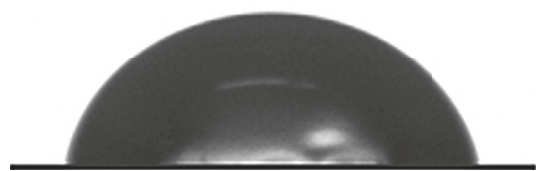

(a)

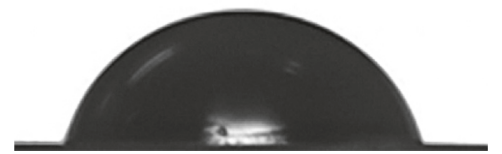

(b)

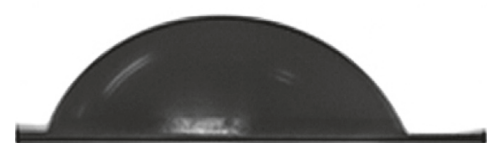

(c)

FIGURE 8: Water contact angle images of (a) PSf, (b) PSf/GO, and (c) PSf/GO-T15 membranes.

TABLE 1: Water contact angle values of PSf, PSf/GO, and PSf/GOT15 membranes.

\begin{tabular}{lccc}
\hline Membranes & PSf & PSf/GO & PSf/GO-T15 \\
\hline WCA $\left({ }^{\circ}\right)$ & 83.4 & 76.2 & 60.2 \\
\hline
\end{tabular}

be increased if the membrane becomes hydrophilic, which can be achieved by blending $\mathrm{GO}$ and $\mathrm{TiO}_{2}$ into the membrane [22]. The normalized permeability between the unblended membrane and the blended membrane at different conditions of $\mathrm{TiO}_{2}$ is shown in Figure 9. There is an increase 


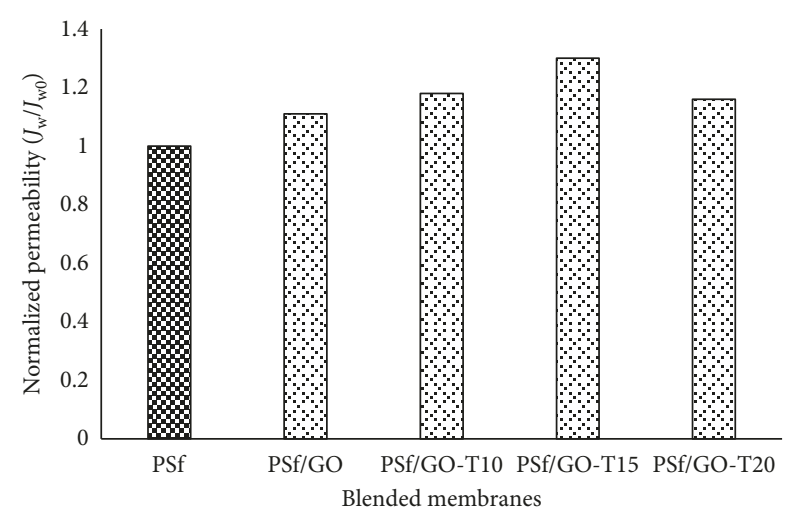

FIGURE 9: Normalized permeability of unblended and blended membranes.

(about 11 to $30 \%$ ) in the permeability in membranes blended with $\mathrm{GO}$ and $\mathrm{TiO}_{2}$ compared to unblended membranes. Thus, the presence of $\mathrm{GO}$ and $\mathrm{TiO}_{2}$ functional groups that contain oxygen caused changes in water permeability. This also corresponds to the results of the WCA.

3.3.2. Separation Performance. Figure 10 shows the experimental results about the separation property of unblended and blended membranes at different conditions of $\mathrm{TiO}_{2}$.

These results show that the flux in the filtrate of the blended membranes could increase dramatically (from 20 to $40 \%$ ) compared to that of the unblended ones. These results are similar to the result of Badrinezhad et al. [1]. By increasing the amount of titanium dioxide, the separation performance of blended membranes is also higher, approximately $20 \%$ higher than unblended ones. This improvement is due to a thin layer of hydration formed on the surface of the membrane caused by hydrogen bonding between water molecules under the influence of oxygencontaining groups. This layer makes the water flux higher. In addition, the retention improves from 38\% to $59 \%$ for the blended membranes. The increase in the retention is due to a hydrophilic thin layer formed, making the membrane surfaces compact.

3.3.3. Antifouling Property. The hydrophilicity also helps mitigate adhesion of foulants and increase the membrane antifouling ability. Figure 11 shows the comparison of the maintained flux ratios of unblended and blended membranes. The results indicate that the flux degradation of the blended membrane is greatly reduced compared to that of the unblended membrane. However, the time required to keep the flow stable is shortened. After 90 min of filtration of the methylene blue feed solution, the flux maintaining ratio of the unblended membrane was about $41 \%$; meanwhile, it was higher than $45 \%$ that of the blended one.

\section{Conclusions}

In this research, the PSf, PSf/GO, and PSf/GO-TiO 2 composite membranes with different ratios of $\mathrm{TiO}_{2}$ are fabricated

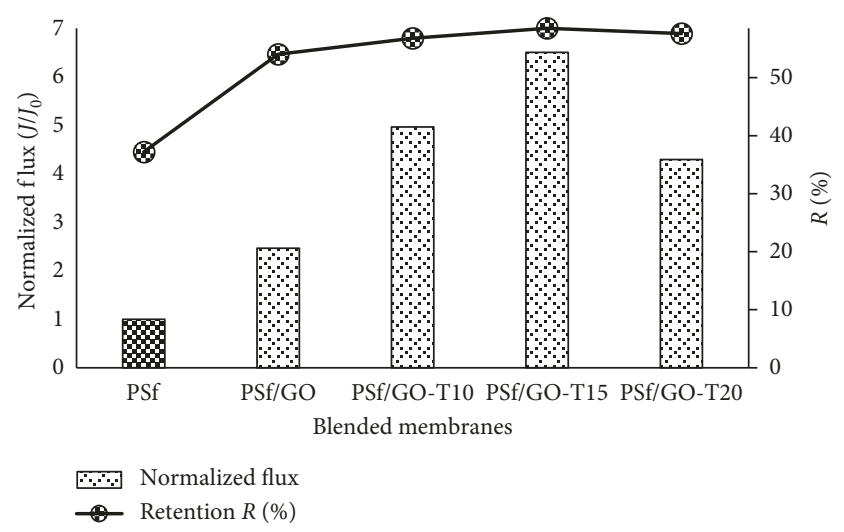

FIgURE 10: Normalized flux and retention of unblended and blended membranes.

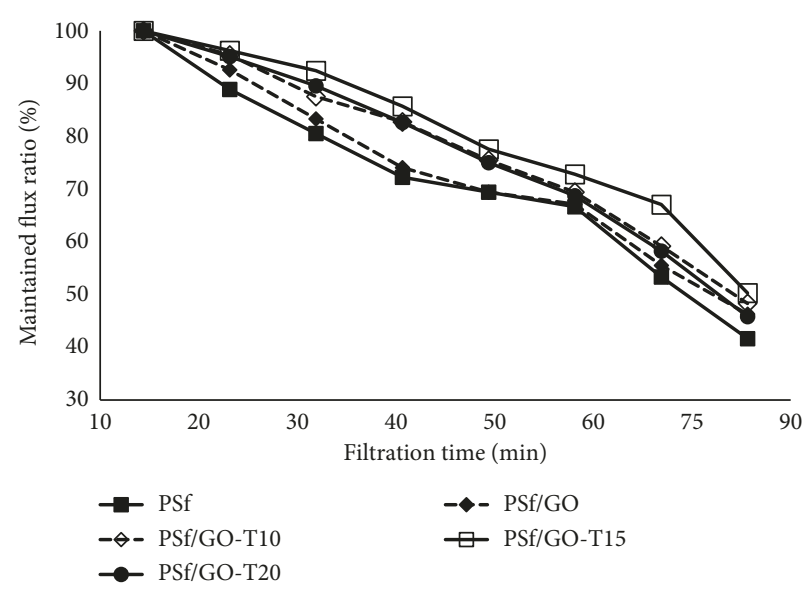

Figure 11: Maintained flux ratio of unblended and blended membranes.

and characterized. The presence of graphene oxide and titanium dioxide in the polysulfone polymer matrix is confirmed by SEM images, EDX spectra, FTIR-ATR spectroscopy, and WCA. The obtained results confirm the appearance of oxygen-containing groups of $\mathrm{GO}$ and $\mathrm{TiO}_{2}$. This makes the blended membrane more hydrophilic with the increase of permeability, retention, flux, and antifouling capacity.

\section{Data Availability}

The data used to support the findings of this study are available from the corresponding author upon request.

\section{Conflicts of Interest}

The authors declare that they have no conflicts of interest.

\section{Acknowledgments}

The authors sincerely thank the National Foundation for Science and Technology Development (NAFOSTED) for financial support under grant no. 104.06-2017.56. 


\section{References}

[1] L. Badrinezhad, S. Ghasemi, Y. Azizian-Kalandaragh, and A. Nematollahzadeh, "Preparation and characterization of polysulfone/graphene oxide nanocomposite membranes for the separation of methylene blue from water," Polymer Bulletin, vol. 75, no. 2, pp. 469-484, 2017.

[2] Y. Kang, M. Obaid, J. Jang, M.-H. Ham, and I. S. Kim, "Novel sulfonated graphene oxide incorporated polysulfone nanocomposite membranes for enhanced-performance in ultrafiltration process," Chemosphere, vol. 207, pp. 581-589, 2018.

[3] M. Ionita, E. Vasile, L. E. Crica et al., "Synthesis, characterization and in vitro studies of polysulfone/graphene oxide composite membranes," Composites Part B: Engineering, vol. 72, pp. 108-115, 2015.

[4] B. M. Ganesh, A. M. Isloor, and A. F. Ismail, "Enhanced hydrophilicity and salt rejection study of graphene oxidepolysulfone mixed matrix membrane," Desalination, vol. 313, pp. 199-207, 2013.

[5] K. B. Prabhu, M. B. Saidutta, A. M. Isloor, and R. Hebbar, "Improvement in performance of polysulfone membranes through the incorporation of chitosan-(3-phenyl-1h-pyrazole-4-carbaldehyde)," Codent Engineering, vol. 4, no. 1, article 1403005, 2017.

[6] H. C. Bidsorkhi, H. Riazi, D. Emadzadeh et al., "Preparation and characterization of a novel highly hydrophilic and antifouling polysulfone/nanoporous $\mathrm{TiO}_{2}$ nanocomposite membrane," Nanotechnology, vol. 27, no. 41, article 415706, 2016.

[7] C. Zhao, X. Xu, J. Chen, and F. Yang, "Effect of graphene oxide concentration on the morphologies and antifouling properties of PVDF ultrafiltration membranes," Journal of Environmental Chemical Engineering, vol. 1, no. 3, pp. 349-354, 2013.

[8] J. Qiu, Y. Zhang, Y. Shen, Y. Zhang, H. Zhang, and J. Liu, "Hydrophilic modification of microporous polysulfone membrane via surface-initiated atom transfer radical polymerization of acrylamide," Applied Surface Science, vol. 256, no. 10, pp. 3274-3280, 2010.

[9] H.-B. Dong, Y.-Y. Xu, Z. Yi, and J.-L. Shi, "Modification of polysulfone membranes via surface-initiated atom transfer radical polymerization," Applied Surface Science, vol. 255, no. 21, pp. 8860-8866, 2009.

[10] M.-L. Luo, J.-Q. Zhao, W. Tang, and C.-S. Pu, "Hydrophilic modification of poly(ether sulfone) ultrafiltration membrane surface by self-assembly of $\mathrm{TiO}_{2}$ nanoparticles," Applied Surface Science, vol. 249, no. 1-4, pp. 76-84, 2005.

[11] A. Rahimpour, S. S. Madaeni, A. H. Taheri, and Y. Mansourpanah, "Coupling $\mathrm{TiO}_{2}$ nanoparticles with UV irradiation for modification of polyethersulfone ultrafiltration membranes," Journal of Membrane Science, vol. 313, no. 1-2, pp. 158-169, 2008.

[12] J.-H. Li, Y.-Y. Xu, L.-P. Zhu, J.-H. Wang, and C.-H. Du, "Fabrication and characterization of a novel $\mathrm{TiO}_{2}$ nanoparticle self-assembly membrane with improved fouling resistance," Journal of Membrane Science, vol. 326, no. 2, pp. 659-666, 2009.

[13] T.-H. Bae and T.-M. Tak, "Effect of $\mathrm{TiO}_{2}$ nanoparticles on fouling mitigation of ultrafiltration membranes for activated sludge filtration," Journal of Membrane science, vol. 249, no. 1-2, pp. 1-8, 2005.

[14] K. C. Chong, S. O. Lai, W. J. Lau, H. S. Thiam, A. F. Ismail, and A. K. Zulhairun, "Fabrication and characterization of polysulfone membranes coated with polydimethysiloxane for oxygen enrichment," Aerosol and Air Quality Research, vol. 17, no. 11, pp. 2735-2742, 2017.

[15] D. J. Miller, D. R. Dreyer, C. W. Bielawski, D. R. Paul, and B. D. Freeman, "Surface modification of water purification membranes: a review," A Journal of the Gesellschaft Deutscher Chemiker, Angewandte Chemie International Edition, vol. 56, no. 17, pp. 4662-4711, 2016.

[16] A. Rahimpour and S. S. Madaeni, "Improvement of performance and surface properties of nano-porous polyethersulfone (PES) membrane using hydrophilic monomers as additives in the casting solution," Journal of Membrane science, vol. 360, no. 1-2, pp. 371-379, 2010.

[17] M. Padaki, A. M. Isloor, G. Belavadi, and K. N. Prabhu, "Preparation, characterization and performance study of poly(isobutylene-alt-maleic anhydride) [PIAM] and polysulfone [PSf] composite membranes before and after alkali treatment," Industrial \& Engineering Chemistry Research, vol. 50, no. 11, pp. 6528-6534, 2011.

[18] B. M. Ganesh, A. M. Isloor, and M. Padaki, "Preparation and characterization of polysulfone and modified poly isobutylene-alt-maleic anhydride blend NF membrane," Desalination, vol. 287, pp. 103-108, 2012.

[19] R. Raslan and A. W. Mohammad, "Polysulfone/pluronic F127 blend ultrafiltration membranes: preparation and characterizations," Journal of Applied Sciences, vol. 10, no. 21, pp. 2628-2632, 2010.

[20] H. Ravishankar, J. Christy, and V. Jegatheesan, "Graphene oxide (GO)-Blended polysulfone (PSf) ultrafiltration membranes for lead ion rejection," Membranes, vol. 8, no. 3, p. 77, 2018.

[21] K. Zodrow, L. Brunet, S. Mahendra et al., "Polysulfone ultrafiltration membranes impregnated with silver nanoparticles show improved biofouling resistance and virus removal," Water Research, vol. 43, pp. 715-723, 2009.

[22] G. S. Lai, W. J. Lau, P. S. Goh, A. F. Ismail, N. Yusof, and Y. H. Tan, "Graphene oxide incorporated thin film nanocomposite nanofiltration membrane for enhanced salt removal performance," Desalination, vol. 387, pp. 14-24, 2016.

[23] L. Yu, Y. Zhang, B. Zhang, J. Liu, H. Zhang, and C. Song, "Preparation and characterization of HPEI-GO/PES ultrafiltration membrane with antifouling and antibacterial properties," Journal of Membrane science, vol. 447, pp. 452-462, 2013.

[24] J. Zhu, M. Tian, J. Hou et al., "Surface zwitterionic functionalized graphene oxide for a novel loose nanofiltration membrane," Journal of Materials Chemistry A, vol. 4, no. 5, pp. 1980-1990, 2016.

[25] H. M. Hegab and L. Zou, "Graphene oxide-assisted membranes: fabrication and potential applications in desalination and water purification," Journal of Membrane Science, vol. 484, pp. 95-106, 2015.

[26] Z. Wang, H. Yu, J. Xia et al., "Novel GO-blended PVDF ultrafiltration membranes," Desalination, vol. 299, pp. 50-54, 2012.

[27] J. Lee, H.-R. Chae, Y. J. Won et al., "Graphene oxide nanoplatelets composite membrane with hydrophilic and antifouling properties for wastewater treatment," Journal of Membrane Science, vol. 448, pp. 223-230, 2013.

[28] J. Zhang, Z. Xu, M. Shan et al., "Synergetic effects of oxidized carbon nanotubes and graphene oxide on fouling control and anti-fouling mechanism of polyvinylidene fluoride ultrafiltration membranes," Journal of Membrane Science, vol. 448, pp. 81-92, 2013. 
[29] J. Wang, Y. Wang, J. Zhu, Y. Zhang, J. Liu, and B. Van der Bruggen, "Construction of $\mathrm{TiO}_{2}$ @graphene oxide incorporated antifouling nanofiltration membrane with elevated filtration performance," Journal of Membrane Science, vol. 533, pp. 279-288, 2017.

[30] L. Duan, Y. Wang, Y. Zhang, and J. Liu, "Graphene immobilized enzyme/polyethersulfone mixed matrix membrane: enhanced antibacterial, permeable and mechanical properties," Applied Surface Science, vol. 355, pp. 436-445, 2015.

[31] F. Perreault, M. E. Tousley, and M. Elimelech, "Thin-film composite polyamide membranes functionalized with biocidal graphene oxide nanosheets," Environmental Science \& Technology Letters, vol. 1, no. 1, pp. 71-76, 2013.

[32] M. Safarpour, A. Khataee, and V. Vatanpour, "Thin film nanocomposite reverse osmosis membrane modified by reduced graphene oxide/ $/ \mathrm{TiO}_{2}$ with improved desalination performance," Journal of Membrane science, vol. 489, pp. 43-54, 2015.

[33] A. F. Faria, C. Liu, M. Xie et al., "Thin-film composite forward osmosis membranes functionalized with graphene oxidesilver nanocomposites for biofouling control," Journal of Membrane science, vol. 525, pp. 146-156, 2017.

[34] T. T. Dung, Surface Modification of RO Membrane by Glow Discharge Plasma, Ph.D. thesis, Tokyo Institute of Technology, Tokyo, Japan, 2001.

[35] K. Norrman, A. Ghanbari-Siahkali, and N. B. Larsen, "6 studies of spin-coated polymer films," Annual Reports Section C, vol. 101, pp. 174-201, 2005.

[36] W. S. Hummers and R. E. Offeman, "Preparation of graphitic oxide," Journal of the American Chemical Society, vol. 80, no. 6, p. 1339, 1958.

[37] L. Guo, P. Ye, J. Wang, F. Fu, and Z. Wu, "Three-dimensional Fe3O4-graphene macroscopic composites for arsenic and arsenate removal," Journal of Hazardous Materials, vol. 298, pp. 28-35, 2015.

[38] P. S. Teo, H. N. Lim, N. M. Huang, C. H. Chia, and I. Harrison, "Room temperature in situ chemical synthesis of $\mathrm{Fe}_{4} \mathrm{O}_{4}$ /graphene," Ceramics International, vol. 38, no. 8, pp. 6411-6416, 2012.

[39] Y. H. Teow, B. S. Ooi, A. L. Ahmad, and J. K. Lim, "Mixedmatrix membrane for humic acid removal: influence of different types of $\mathrm{TiO}_{2}$ on membrane morphology and performance," International Journal of Chemical Engineering and Applications, vol. 3, no. 6, pp. 374-379, 2012.

[40] K. E. Tettey, M. Q. Yee, and D. Lee, "Photocatalytic and conductive $\mathrm{MWCNT} / \mathrm{TiO}_{2}$ nanocomposite thin films," ACS Applied Materials \& Interfaces, vol. 2, no. 9, pp. 2646-2652, 2010. 

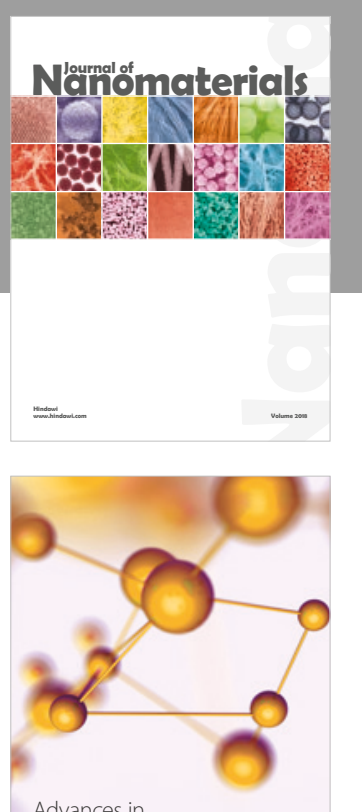

Physical Chemistry
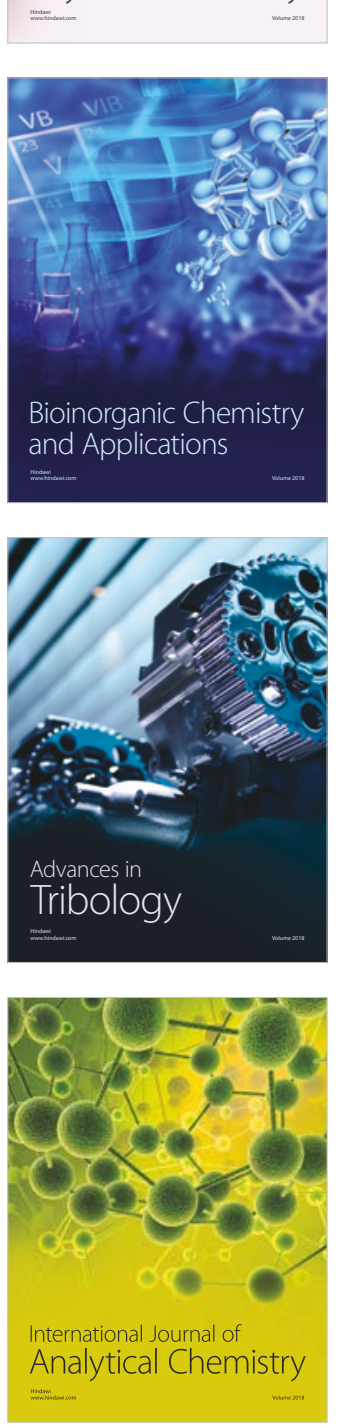

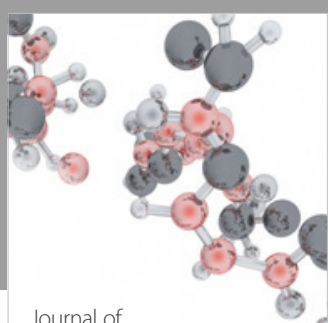

Analytical Methods

in Chemistry

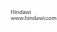

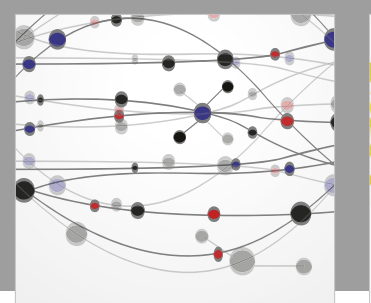

The Scientific World Journal

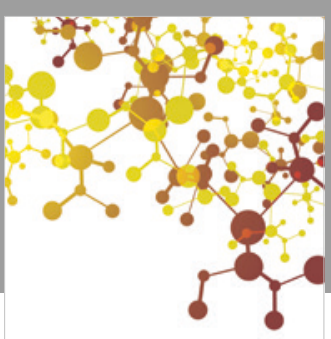

Journal of

Applied Chemistry
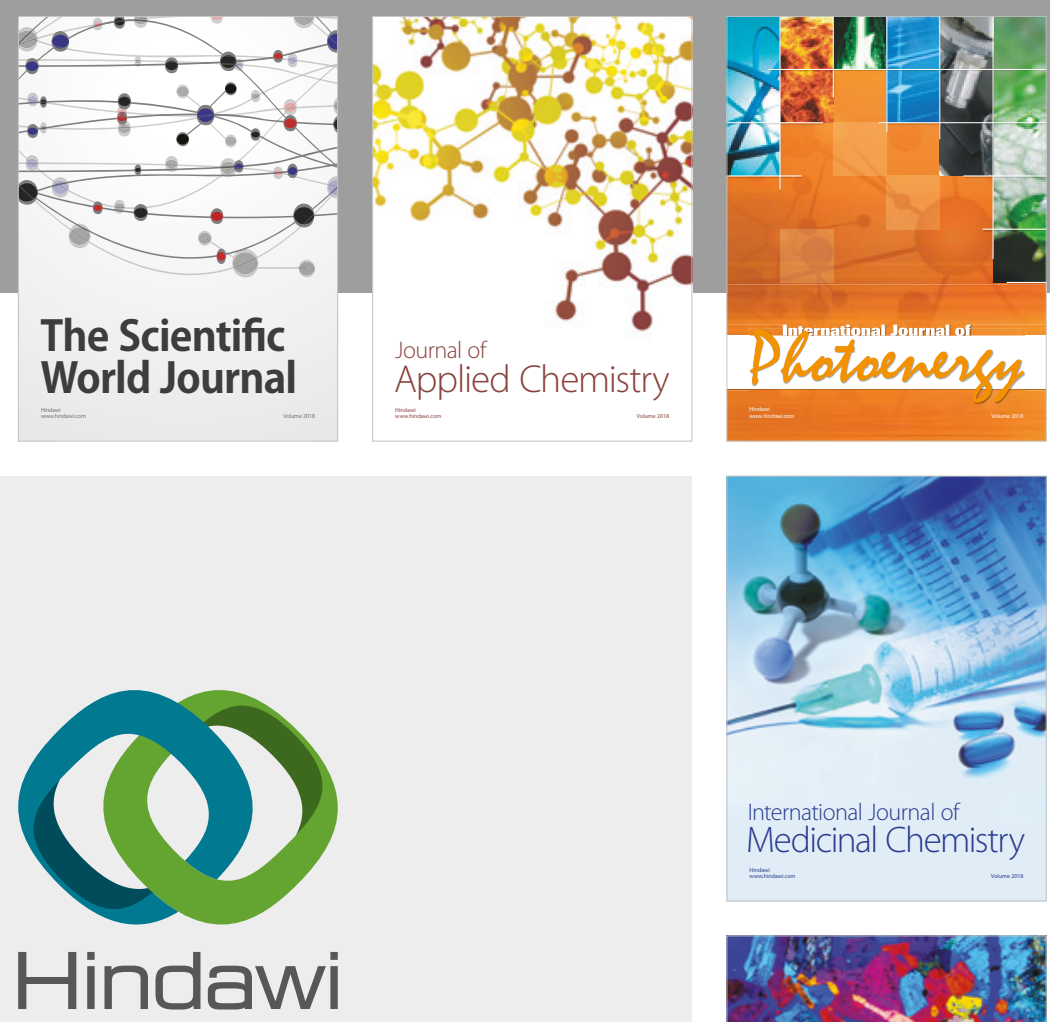

Submit your manuscripts at

www.hindawi.com
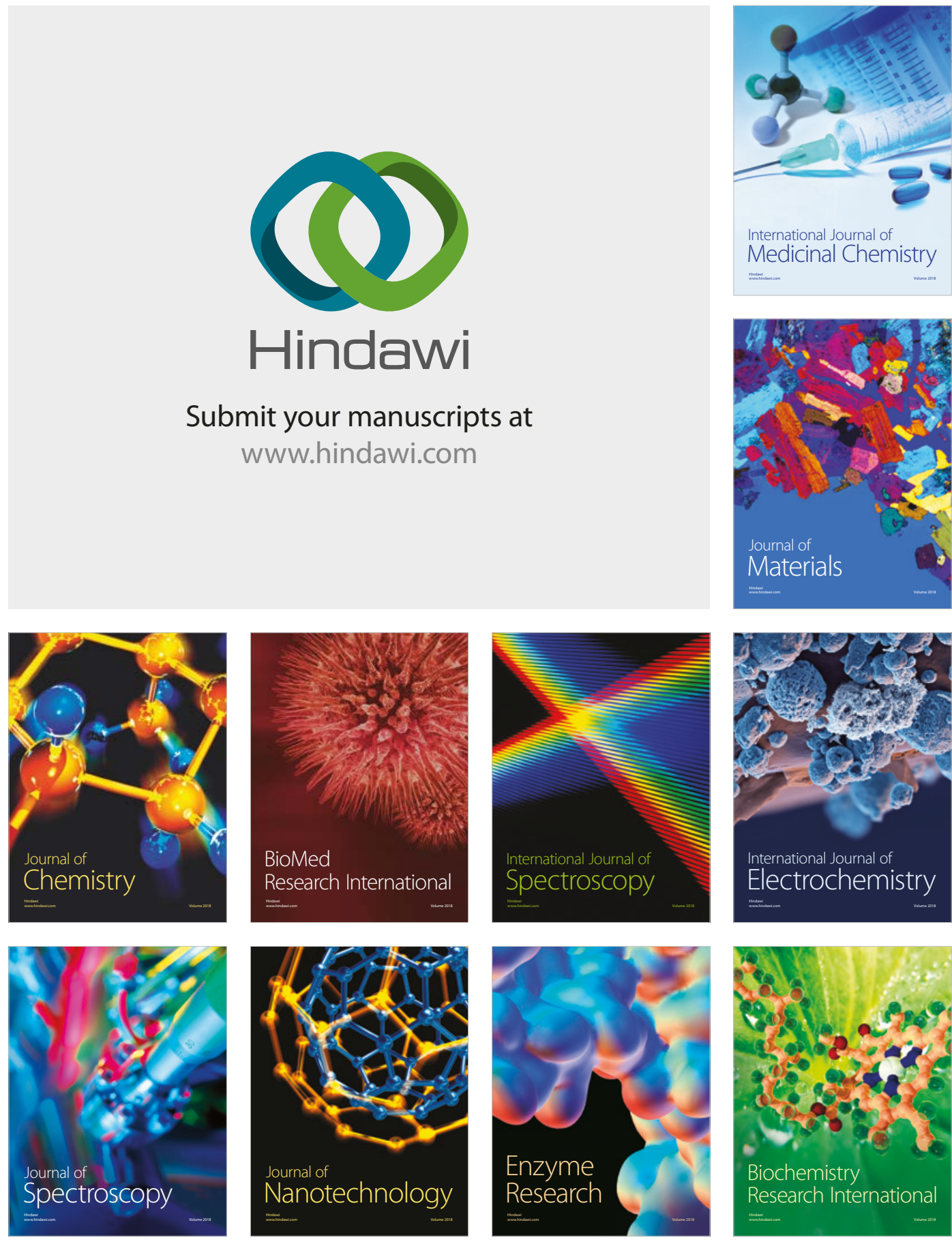
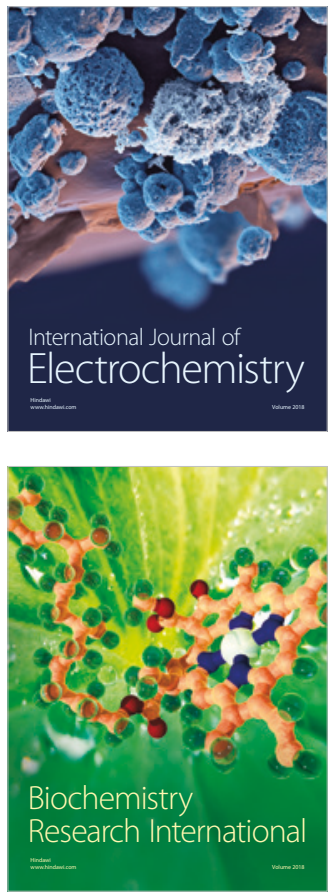